\title{
Comparison of results from two antibiotic susceptibility testing trials that formed part of the United Kingdom national external quality assessment scheme
}

\author{
JJS SNELL, DFJ BROWN, * PS GARDNER
}

From the Division of Microbiological Reagents and Quality Control, Central Public Health Laboratory, Colindale, London NW9 5HT, and the *Regional Public Health Laboratory, Addenbrooke's Hospital, Hills Road, Cambridge CB2 $2 Q W$

SUMMARY A susceptibility testing trial that formed part of the United Kingdom national external quality assessment scheme has been described previously. ${ }^{1}$ Results from this first trial showed an association between error rates and particular methods and practices. Changes in methods were recommended where appropriate. A second trial and survey of methods has shown reluctance to change methods and confirmed in most cases that high error rates were associated with the same methods and practices indicated by the first trial. Recommendations on disc content, method of methicillin testing, preparation of inoculum, use of controls and use of lysed blood for sulphonamide testing based on the results from these two trials are restated to encourage laboratories to review their methods critically. A statistical analysis of the results showed significant differences in performance among laboratories, and laboratories whose performance was significantly below the mean were identified. Poor performance was associated with the use of unsatisfactory methods. In view of the critical importance of susceptibility testing in patient care it is intended to use the results of susceptibility testing in the assessment of the performance of laboratories participating in the UK national external quality assessment scheme.

The ability of laboratories to test susceptibility of bacteria to antibiotics has been evaluated since 1974 as part of the UK national external microbiological quality assessment scheme. A high overall error rate, particularly pronounced with some combinations of strain and drug, has always given cause for concern. In an attempt to ascertain the causes of these errors a trial scheme was implemented during 1980-1. The results of this trial' showed an association between certain methods and practices and error rates. Since the causes of these errors were for the most part well known, we believed that we were justified in recommending changes in methodology where appropriate. ${ }^{1}$ In order to investigate whether these changes had been implemented and whether standards of performance had improved a further trial was carried out during 1982.

Accepted for publication 28 November 1983

\section{Material and methods}

\section{LABORATORIES PARTICIPATING}

All laboratories enrolled in the UK national external microbiological quality assessment scheme and accepting bacteriology specimens were included in the trial (467 laboratories in January 1982). These laboratories, with a few additions, were the same as those taking part previously.' The type of laboratories and their geographical distribution have been described previously. ${ }^{2}$ Owing to changes in the international postal regulations taking effect during this trial, it was not possible to send specimens to some foreign laboratories during part of the trial. This resulted in some missing data, which is apparent in the response rates shown in some of the tables.

ORGANISMS

The bacteria distributed and the antibiotics to be 
Table 1 Reference laboratories' and participants' results for the strains distributed

\begin{tabular}{|c|c|c|c|c|c|c|}
\hline & \multirow[t]{2}{*}{$\begin{array}{l}\text { MICs determined } \\
\text { by reference } \\
\text { laboratories } \\
\text { (mg/l) }\end{array}$} & \multirow[t]{2}{*}{$\begin{array}{l}\text { Designated } \\
\text { correct } \\
\text { result }\end{array}$} & \multicolumn{3}{|c|}{$\begin{array}{l}\text { No of } \\
\text { laboratories } \\
\text { reporting strain as }\end{array}$} & \multirow[t]{2}{*}{$\begin{array}{l}\text { \% of laboratories } \\
\text { correct }\end{array}$} \\
\hline & & & $\boldsymbol{S}$ & $\boldsymbol{I}$ & $\boldsymbol{R}$ & \\
\hline \multicolumn{7}{|c|}{$\begin{array}{l}\text { Ps aeruginosa MQCL } 61 \text { (derived from NCTC 10662, the recommended control strain for sensitivity tests). Site: other than urine. Combined } \\
\text { results from two distributions }\end{array}$} \\
\hline $\begin{array}{l}\text { Carbenicillin } \\
\text { Gentamicin } \\
\text { Tobramycin } \\
\text { Amikacin }\end{array}$ & $\begin{array}{l}32 / 32 \\
0 \cdot 5 / 1 \\
0 \cdot 25 / 0 \cdot 25 \\
1 / 2\end{array}$ & $\begin{array}{l}\mathbf{S} \\
\mathbf{S} \\
\mathbf{S} \\
\mathbf{S}\end{array}$ & $\begin{array}{l}718 \\
849 \\
838 \\
770\end{array}$ & $\begin{array}{r}44 \\
37 \\
7 \\
53\end{array}$ & $\begin{array}{r}50 \\
23 \\
1 \\
18\end{array}$ & $\begin{array}{l}88 \cdot 4 \\
93 \cdot 4 \\
99 \cdot 1 \\
91 \cdot 6\end{array}$ \\
\hline \multicolumn{7}{|c|}{ Ps aeruginosa MQCL 356. Site: other than urine } \\
\hline Carbenicillin & $32 / 32$ & $\mathbf{S}$ & 333 & 20 & 19 & $89 \cdot 5$ \\
\hline Gentamicin & $0 \cdot 5 / 0 \cdot 5$ & $\mathbf{S}$ & 407 & 4 & 1 & $98 \cdot 8$ \\
\hline Tobramycin & $0 \cdot 25 / 0 \cdot 25$ & $\mathbf{S}$ & 389 & 1 & 1 & $97 \cdot 0$ \\
\hline Amikacin & $2 / 2$ & $\mathbf{S}$ & 380 & 2 & 0 & $99 \cdot 5$ \\
\hline \multicolumn{7}{|c|}{$S$ aureus $M Q C L$ 360. Site: other than urine } \\
\hline $\begin{array}{l}\text { Gentamicin } \\
\text { Penicillin }\end{array}$ & $0 \cdot 125 / 0 \cdot 125$ & $\mathbf{S}$ & 447 & 4 & $\begin{array}{r}0 \\
13\end{array}$ & $\begin{array}{l}99 \cdot 1 \\
97 \cdot 1\end{array}$ \\
\hline $\begin{array}{l}\text { Penicillin } \\
\text { Methicillin }\end{array}$ & $0 \cdot 06 / 0 \cdot 06$ & $\mathbf{S}$ & $\begin{array}{l}441 \\
443\end{array}$ & $\begin{array}{l}0 \\
0\end{array}$ & $\begin{array}{r}13 \\
0\end{array}$ & $\begin{array}{l}97 \cdot 1 \\
100\end{array}$ \\
\hline $\begin{array}{l}\text { Methicillin } \\
\text { Tetracycline }\end{array}$ & $\begin{array}{l}2 / 2 \\
0.25 / 0 \cdot 5\end{array}$ & $\overrightarrow{\mathbf{S}}$ & $\begin{array}{l}443 \\
426\end{array}$ & 14 & 3 & $\begin{array}{c}100 \\
96 \cdot 2\end{array}$ \\
\hline $\begin{array}{l}\text { Tetracycline } \\
\text { Erythromycin }\end{array}$ & $0.25 / 0 \cdot 25$ & $\mathbf{S}$ & 448 & 5 & 0 & 98.2 \\
\hline Fusidic acid & $0 \cdot 1 / 0 \cdot 25$ & $\mathbf{S}$ & 437 & 4 & 0 & $99 \cdot 1$ \\
\hline \multicolumn{7}{|c|}{$S$ aureus MQCL 192. Site: other than urine } \\
\hline Gentamicin & $0.06 / 0.25$ & $\mathbf{S}$ & 417 & 5 & 1 & $98 \cdot 6$ \\
\hline Penicillin & $8 / 16$ & $\mathbf{R}$ & 3 & 2 & 420 & $98 \cdot 8$ \\
\hline Methicillin & $16 / 32$ & $\mathbf{R}$ & 50 & 11 & 350 & $85 \cdot 2$ \\
\hline Tetracycline & $64 / 64$ & $\mathbf{R}$ & 4 & 0 & 413 & $99 \cdot 0$ \\
\hline Erythromycin & $2 / 4$ & $\mathbf{R}^{*}$ & 17 & 24 & 383 & $90 \cdot 3$ \\
\hline Fusidic acid & $0.03 / 0 \cdot 06$ & $\mathbf{S}$ & 408 & 5 & 4 & $97 \cdot 8$ \\
\hline \multicolumn{7}{|c|}{ St faecalis MQCL 609. Site: urine. Combined results from two distributions } \\
\hline Gentamicin & $4 / 8$ & $\mathrm{ND} \dagger$ & 263 & 183 & 441 & - \\
\hline Ampicillin & $1 / 2$ & $\mathbf{S}$ & 876 & 20 & 4 & $97 \cdot 3$ \\
\hline Cephalexin & $128 / 128$ & $\mathbf{R}$ & 19 & 6 & 583 & 95.9 \\
\hline Sulphonamide & $>512 />512$ & $\mathbf{R}$ & 6 & 2 & 871 & $99 \cdot 1$ \\
\hline Trimethoprim & $0 \cdot 5 / 0 \cdot 5$ & $\mathbf{S}$ & 653 & 52 & 164 & $75 \cdot 1$ \\
\hline Cotrimoxazole & NT/NT & ND $\ddagger$ & 413 & 37 & 258 & - \\
\hline \multicolumn{7}{|c|}{ Pr mirabilis MQCL 11. Site: urine } \\
\hline Gentamicin & $0 \cdot 25 / 1$ & $\mathbf{S}$ & 429 & 0 & 3 & $99 \cdot 3$ \\
\hline Ampicillin & $2 / 2$ & $\mathbf{S}$ & 428 & 2 & 4 & $\mathbf{9 8 \cdot 6}$ \\
\hline Cephalexin & $8 / 16$ & $\mathbf{S}$ & 255 & 19 & 24 & $85 \cdot 6$ \\
\hline Sulphonamide & $4 / 2$ & $\mathbf{S}$ & 352 & 12 & 57 & 83.6 \\
\hline Trimethoprim & $1 / 2$ & S\$ & 275 & 50 & 92 & $74 \cdot 1$ \\
\hline Cotrimoxazole & NT/NT & $\mathbf{S \|}$ & 309 & 10 & $3 \overline{5}$ & $87 \cdot 3$ \\
\hline \multicolumn{7}{|c|}{ Escherichia coli MQCL 116. Site: urine } \\
\hline Gentamicin & $0 \cdot 06 / 0 \cdot 25$ & $\mathbf{S}$ & 435 & 2 & 2 & $99 \cdot 1$ \\
\hline Ampicillin & $4 / 4$ & $\mathbf{S}$ & 413 & 13 & 15 & $93 \cdot 7$ \\
\hline Cephalexin & $4 / 8$ & $\mathbf{S}$ & 276 & 17 & 7 & $92 \cdot 0$ \\
\hline Sulphonamide & $4 / 4$ & $\mathbf{S}$ & 411 & 2 & 20 & $94 \cdot 9$ \\
\hline Trimethoprim & $0 \cdot 125 / 0 \cdot 125$ & $\mathbf{S}$ & 417 & 4 & 4 & $98 \cdot 1$ \\
\hline Cotrimoxazole & NT/NT & $\mathbf{S}$ & 367 & 1 & 5 & $98 \cdot 4$ \\
\hline \multicolumn{7}{|c|}{ E coli MQCL 60 (derived from NCTC 10418, the recommended control strain for sensitivity tests). Site: urine } \\
\hline Gentamicin & $0 \cdot 125 / 0 \cdot 5$ & $\mathrm{~S}$ & 420 & 4 & 1 & $98 \cdot 8$ \\
\hline Ampicillin & $2 / 4$ & $\mathbf{S}$ & 417 & 6 & 5 & $97 \cdot 4$ \\
\hline Cephalexin & $8 / 8$ & $\mathbf{S}$ & 273 & 10 & 5 & $94 \cdot 8$ \\
\hline Sulphonamide & $2 / 8$ & $\mathbf{S}$ & 384 & 7 & 23 & $92 \cdot 8$ \\
\hline Trimethoprim & $0 \cdot 125 / 0 \cdot 125$ & $\mathbf{S}$ & 403 & 1 & 5 & $98 \cdot 5$ \\
\hline Cotrimoxazole & NT/NT & $\mathbf{S}$ & 352 & 1 & 6 & $98 \cdot 1$ \\
\hline \multicolumn{7}{|c|}{ Klebsiella sp MQCL 200. Site: urine. Combined results from two distributions } \\
\hline Gentamicin & $<0.06 / 0.06$ & $\mathrm{~S}$ & 859 & 0 & 2 & $99 \cdot 8$ \\
\hline Ampicillin & $>128 />128$ & $\mathbf{R}$ & 11 & 2 & 854 & $98 \cdot 5$ \\
\hline Cephalexin & $4 / 4$ & $\mathbf{S}$ & 586 & 17 & 12 & $95 \cdot 3$ \\
\hline Sulphonamide & $32 / 32$ & ND & 582 & 53 & 212 & - \\
\hline Trimethoprim & $0.5 / 0.5$ & $\mathbf{S}$ & 678 & 95 & 63 & $81 \cdot 1$ \\
\hline Cotrimoxazole & NT/NT & ND & 615 & 29 & 60 & - \\
\hline
\end{tabular}

MIC = minimum inhibitory concentration; $S=$ sensitive; $I=$ intermediate; $R=$ resistant; $N T=$ not tested; ND = not designated.

*This strain showed dissociated resistance to erythromycin.

tAt the time of the trial a resistant or intermediate result for gentamicin was designated as correct. Expert opinion differed greatly on the correct designation of this strain, however, and for the purpose of this analysis a correct result was not designated.

$\ddagger A$ correct result was not designated for cotrimoxazole with this strain because it was sensitive to trimethoprim but resistant to sulphonamide.

\$Participants were not scored on their results for trimethoprim with this strain because, although the strain was sensitive to trimethoprim for the species, it was more resistant than many coliforms. For the purpose of the analysis the strain was regarded as sensitive.

Participants were not scored on their results for cotrimoxazole during the trial because of the difficulties of interpreting the various testing and reporting conventions used for this combination. 
tested are shown in Table 1 . The drug susceptibility characteristics of the strains were determined as described previously' and are also shown in Table 1. Strains were sent to participants at roughly monthly intervals from January 1982 to January 1983.

\section{QUESTIONNAIRE}

A questionnaire on methods was sent to all participants at the beginning of the trial. The questionnaire was essentially the same as that used earlier,' modified as necessary in order to elucidate further details of methods not fully covered in the previous questionnaire.

\section{SCORING SCHEME}

Laboratories were given a score of 2 for a correct result and $\mathbf{0}$ for an incorrect result, as described previously.' We envisaged that a score of 1 might be used in some circumstances, but this was not used during this trial. After each distribution, participants were notified of the overall results of all participants for each specimen, their own results for the current specimen, and their own cumulative results for the series. The performance of laboratories from the UK and Eire (that is, those served by the Advisory Panel for Microbiology) was assessed for each of the two six month periods of the trial by comparing each laboratory's cumulative results with the mean results calculated from the reports of all laboratories reporting on the same combinations of antibiotic and organism. Cochran's $\chi^{2}$ test was used to test whether there were significant differences in performance among laboratories before the performance of each individual laboratory was calculated. Calculations were performed as described previously. ${ }^{23}$ Laboratories with cumulative scores more than 1.96 standard errors below the mean were considered possible "poor performers."

\section{Results}

\section{DISCREPANCY RATES}

Participants' results and error rates are shown in Table 1. The overall error rate for the series (1399 incorrect results, 22293 correct results) was 5.9\% compared with $7.1 \%$ in the previous trial. The results are not directly comparable, however, as different strains were used in the two trials. One strain each of Pseudomonas aeruginosa (MQCL 356) and Proteus mirabilis (MQCL 11) and two strains of Staphylococcus aureus (MQCL 360, 192) were, however, included in both trials. After averaging the results from two distributions for the $\operatorname{Pr}$ mirabilis and $S$ aureus MQCL 192, the results for these strains in the first trial were 584 incorrect and 8755 correct results $(94 \%$ correct); in the second trial

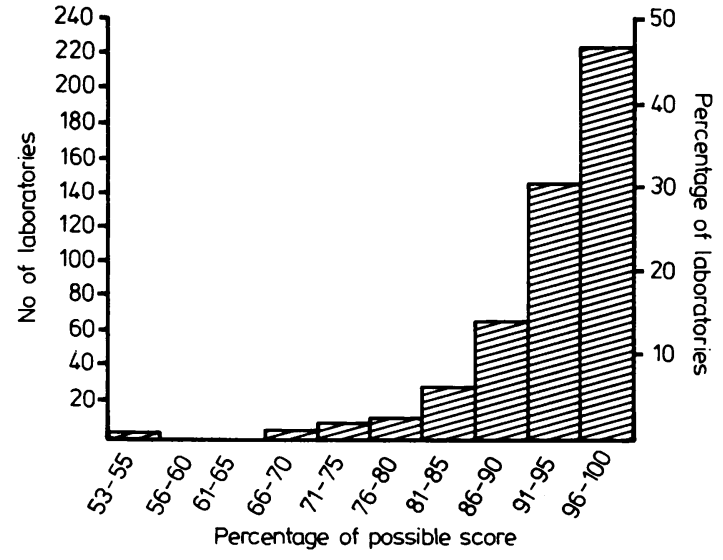

Number and percentage of laboratories achieving various percentages of their total possible scores

there were 525 incorrect and 8590 correct results ( $94 \%$ correct). There is no significant difference between these error rates. High error rates of greater than $5 \%$ were mostly associated with the same antibiotics as in the previous trial: trimethoprim $(17.9 \%)$, carbenicillin $(11.2 \%)$, methicillin $(7 \cdot 1 \%)$, cephalexin $(6.4 \%)$, sulphonamide $(6.0 \%)$, amikacin $(5.9 \%)$, cotrimoxazole $(5.3 \%)$, and erythromycin $(5 \cdot 2 \%)$. The number of laboratories achieving various percentages of their total possible scores is shown in the Figure. This distribution is similar to that shown in the previous trial with $20 \%$ of laboratories achieving less than $90 \%$ correct. A comparison of the percentages of possible scores achieved by laboratories taking part in both trials showed a correlation coefficient of 0.48 for the 453 comparisons, suggesting significant association of performance in the two trials $(p<0.001)$.

\section{CHANGES IN METHODS}

The analysis of the 1980 trial showed that certain methods and practices were associated with incorrect results. Several recommendations were made on the basis of these results (Table 2), but few laboratories implemented these recommendations. The only apparent change is in the increase in the number of laboratories standardising the inoculum. It is probable that this is a spurious result caused by differences in wording between the two questionnaires. In the earlier questionnaire participants were simply asked if the inoculum was standardised with no mention made of methods of standardisation. In the second questionnaire several different methods of standardisation were presented, including "by eye." It is possible that laboratories filling in the earlier questionnaire as not standardising their 
Table 2 Changes in methods used by laboratories following recommendations from the first trial

\begin{tabular}{|c|c|c|}
\hline & \multicolumn{2}{|c|}{ No of laboratories using method in } \\
\hline & 1980 trial & 1982 trial \\
\hline \multicolumn{3}{|l|}{ Ampicillin disc content for strains from urine } \\
\hline High $(25,30 \mu \mathrm{g})^{*}$ & $319(91 \%)$ & $332(89 \%)$ \\
\hline \multicolumn{3}{|l|}{ Carbenicillin disc content for $P$ s aeruginosa } \\
\hline $\begin{array}{l}\text { High }(100,200 \mu \mathrm{g})^{*} \\
\text { Low }(10,25,50 \mu \mathrm{g})\end{array}$ & $\underset{41}{282}(87 \%)$ & $274(90 \%)$ \\
\hline \multicolumn{3}{|l|}{ Erythromycin disc content for $S$ aureus } \\
\hline $\begin{array}{l}\text { High }(10,15 \mu \mathrm{g}) \\
\operatorname{Low}(2,2 \cdot 5,5 \mu \mathrm{g})^{*}\end{array}$ & $145(59 \%)$ & 158 \\
\hline \multicolumn{3}{|l|}{ Use of $\mathrm{NaCl}$ or incubation at $30^{\circ} \mathrm{C}$ for methicillin testing } \\
\hline $\begin{array}{l}\text { Either or both used* } \\
\text { Neither used }\end{array}$ & $326(88 \%)$ & $361(92 \%)$ \\
\hline \multicolumn{3}{|l|}{ Standardisation of inoculum } \\
\hline Inoculum standardised ${ }^{*}$ & $315(86 \%)$ & $391(96 \%)$ \\
\hline Inoculum not standardised & 52 & $16(200)$ \\
\hline \multicolumn{3}{|l|}{ Preparation of inoculum } \\
\hline Inoculum direct from colony & 28 & 28 \\
\hline \multicolumn{2}{|l|}{ Application of inoculum } & $350(92 \%)$ \\
\hline By loop followed by swab* & $70(19 \%)$ & $75(19 \%)$ \\
\hline Other method & 298 & $313(1210)$ \\
\hline \multicolumn{3}{|l|}{ Use of controls } \\
\hline Controls used* & $347(92 \%)$ & $388(95 \%)$ \\
\hline Controls not used & 32 & 20 \\
\hline \multicolumn{3}{|l|}{ Use of lysed blood by laboratories using DST } \\
\hline Lysed blood used* & $143(72 \%)$ & $129(72 \%)$ \\
\hline $\begin{array}{l}\text { Lysed blood not used } \\
\text { Use of Mueller-Hinton agar }\end{array}$ & 54 & 49 \\
\hline \multicolumn{3}{|l|}{ Use of Mueller-Hinton agar } \\
\hline Used with non-Kirby-Bauer type method $\dagger$ & NA & $13(300)$ \\
\hline
\end{tabular}

*Recommended method.

In view of the apparent association of incorrect results with the use of Mueller-Hinton agar it was recommended that this medium should be used only with methods specifying its use (for example, Kirby-Bauer type methods).

NA = information not available.

inocula changed their response to "by eye" in the second.

\section{MEDIA}

More specific wording of the questionnaire allowed the identification of more individual types of media than in the previous trial. Differences in the ratios of right and wrong results obtained with various media are generally similar to those found in the previous trial but fewer differences were significant (Table 3). STA medium (London Analytical and Bacteriological Media) performed well again and MuellerHinton performed badly. The use of DST (Tissue Culture Services) seemed to be associated with high

Table 3 Distribution of incorrect results according to media used (combined results for all specimens and antibiotics)

\begin{tabular}{lcccc}
\hline $\begin{array}{l}\text { Medium used } \\
\text { (manufacturer) }\end{array}$ & $\begin{array}{l}\text { No of } \\
\text { laboratories }\end{array}$ & \multicolumn{2}{c}{ No of results } & \multicolumn{2}{c}{$\begin{array}{c}\text { Ratio of } \\
\text { right:wrong }\end{array}$} \\
\cline { 2 - 5 } & & Right & Wrong & \\
\hline DST (Oxoid) & 151 & 6917 & 368 & 19 \\
DST/SAF (Mast) & 11 & 393 & 23 & 17 \\
Sensitest (Oxoid) & 15 & 639 & 36 & 18 \\
Isosensitest (Oxoid) & 120 & 5071 & 251 & 20 \\
Mueller-Hinton (various) & 29 & 1009 & 85 & 12 \\
STA (London Analytical and Bacteriological Media) & 20 & 975 & 33 & 30 \\
DST (Gibco) & 15 & 759 & 45 & 17 \\
DST (Tissue Culture Services) & 9 & 415 & 49 & 8 \\
\hline
\end{tabular}

Significant differences in error rates

DST (Oxoid) < Mueller-Hinton $\left(\chi^{2} 13.74, p<0.001\right)$ and DST (TCS) $\left(\chi^{2} 25.99, p<0.001\right)$.

DST/SAF (Mast) < DST (TCS) $\left(\chi^{2} 7 \cdot 39, \mathrm{p}<0.01\right)$.

Sensitest $<$ Mueller-Hinton $\left(\chi^{2} 3.89, \mathrm{p}<0.05\right)$ and DST (TCS) $\left(\chi^{2} 10.87, \mathrm{p}<0.001\right)$.

Isosensitest $<$ Mueller-Hinton $\left(\chi^{2} 17.05, \mathrm{p}<0.001\right)$ and DST (TCS) $\left(\chi^{2} 29.65, \mathrm{p}<0.001\right)$.

DST Gibco < DST (TCS) $\left(\chi^{2} 10.56, \mathrm{p}<0.001\right)$.

STA (Lab M) < DST (Oxoid) $\left(\chi^{2} 6.08, \mathrm{p}<0.05\right)$ and DST/SAF (Mast) $\left(\chi^{2} 3.96, \mathrm{p}<0.05\right)$ and Sensitest $(O x o i d)\left(\chi^{2} 4.36, \mathrm{p}<0.05\right)$ and Isosensitest $\left(\chi^{2} 4 \cdot 11, \mathrm{p}<0.05\right)$ and Mueller-Hinton $\left(\chi^{2} 20 \cdot 01, \mathrm{p}<0.001\right)$ and DST (TCS) $\left(\chi^{2} 32 \cdot 07, \mathrm{p}<0.001\right)$ and DST (Gibco) $\left(\chi^{2} 5 \cdot 86\right.$, $\mathrm{p}<0.05$ ) 
Table 4 Distribution of incorrect results for sulphonamide, trimethoprim, and cotrimoxazole according to use of media with or without lysed blood (combined results from relevant specimens)

\begin{tabular}{|c|c|c|c|c|c|c|c|}
\hline \multirow[t]{2}{*}{ Medium } & \multirow{2}{*}{$\begin{array}{l}\text { Lysed } \\
\text { blood } \\
\text { used }\end{array}$} & \multirow{2}{*}{$\begin{array}{l}\text { No of } \\
\text { laboratories }\end{array}$} & \multicolumn{2}{|c|}{ No of results } & \multirow{2}{*}{$\begin{array}{l}\text { Ratio of } \\
\text { right:wrong }\end{array}$} & \multirow[t]{2}{*}{$x^{2}$} & \multirow[t]{2}{*}{$p$} \\
\hline & & & Right & Wrong & & & \\
\hline \multirow[t]{2}{*}{ DST (Oxoid) } & No & 40 & 437 & 73 & 6 & $5 \cdot 48$ & $<0.05$ \\
\hline & Yes & 109 & 1259 & 147 & 9 & & \\
\hline \multirow[t]{2}{*}{ DST/SAF (Mast) } & No & 5 & 37 & 5 & 7 & $7 \cdot 1$ & $<0.01$ \\
\hline & Yes & 6 & 57 & 0 & - & & \\
\hline \multirow[t]{2}{*}{ Sensitest (Oxoid) } & No & 11 & 123 & 12 & 10 & $0 \cdot 52$ & NS \\
\hline & Yes & $\begin{array}{r}4 \\
81\end{array}$ & 36 & 2 & 18 & & \\
\hline Isosensitest (Oxoid) & Yes & $\begin{array}{l}81 \\
37\end{array}$ & $\begin{array}{l}822 \\
423\end{array}$ & $\begin{array}{l}69 \\
45\end{array}$ & $\begin{array}{r}12 \\
9\end{array}$ & $1 \cdot 39$ & NS \\
\hline \multirow[t]{2}{*}{ Mueller-Hinton (various) } & No & 23 & 195 & 26 & 8 & 0.04 & NS \\
\hline & Yes & 6 & 48 & 7 & 7 & & \\
\hline \multirow{2}{*}{$\begin{array}{l}\text { STA (London Analytical and } \\
\text { Bacteriological Media) }\end{array}$} & No & 5 & 64 & & & & \\
\hline & Yes & $\begin{array}{r}5 \\
15\end{array}$ & $\begin{array}{r}04 \\
185\end{array}$ & 20 & $\begin{array}{r}13 \\
9\end{array}$ & 0.39 & NS \\
\hline \multirow[t]{2}{*}{ DST (Gibco) } & No & 4 & 34 & 11 & 3 & $7 \cdot 87$ & $<0.01$ \\
\hline & Yes & 11 & 144 & 14 & 10 & & \\
\hline \multirow[t]{2}{*}{ DST (Tissue Culture Services) } & No & 3 & 29 & 13 & 2 & 0.44 & NS \\
\hline & Yes & 6 & 59 & 20 & 3 & & \\
\hline
\end{tabular}

NS $=$ not significant

error rates, but as only a few laboratories were using this medium the effect of other factors cannot be excluded.

\section{USE OF LYSED BLOOD}

The addition of lysed blood reduced the number of errors in sulphonamide testing with most DST media (Table 4).

\section{METHODS FOR TESTING METHICILLIN}

\section{SUSCEPTIBILITY}

With the methicillin resistant strain fewer reports of false sensitivity (42 incorrect, 254 correct results) were made by the laboratories using media supplemented with $\mathrm{NaCl}$ or incubating at $30^{\circ} \mathrm{C}$ or both than the laboratories using neither of these methods ( six incorrect, nine correct results: $\chi^{2}$ 7.2, $p<$ ().(0)1).

INOCULUM PREPARATION

The effect of different methods of standardising the inoculum were investigated in this trial (Table 5). Laboratories using opacity tubes made fewer errors than those not standardising the inoculum or standardising "by eye" only $\left(\chi^{2} 4 \cdot 53, p<0 \cdot 05\right)$ or those using measured dilution of broth culture $\left(\chi^{2} 4 \cdot 71, p\right.$ $<0.05)$.

In contrast to the previous trial there was no significant difference in the ratio of correct to incorrect results between the 28 laboratories using colonies directly as an inoculum (69 incorrect, 1215 correct results) and the $\mathbf{3 5 0}$ laboratories emulsifying growth in fluid or subculturing to broth before inoculation (856 incorrect, 15135 correct results). The distribution of correct and incorrect results according to the method of applying the inoculum is shown in Table 6. As in the previous trial fewer errors were made by laboratories applying the inoculum with a loop and then spreading with a swab than by those inoculating by loop alone $\left(\chi^{2}\right.$ $10 \cdot 82, \mathrm{p}<0.01)$ or by swab alone $\left(\chi^{2} 8.23, \mathrm{p}<\right.$ $0 \cdot 01)$.

Table 5 Distribution of incorrect results according to method of standardising the inoculum (combined results for all specimens)

\begin{tabular}{|c|c|c|c|c|}
\hline \multirow[t]{2}{*}{ Method of standardising inocula } & \multirow{2}{*}{$\begin{array}{l}\text { No of } \\
\text { laboratories }\end{array}$} & \multicolumn{2}{|c|}{ No of results } & \multirow{2}{*}{$\begin{array}{l}\text { Ratio of } \\
\text { right:wrong }\end{array}$} \\
\hline & & Right & Wrong & \\
\hline \multirow{2}{*}{$\begin{array}{l}\text { Not standardised or "by eye" only } \\
\text { By opacity tubes } \\
\text { Measured dilution of broth culture } \\
\text { Fixed number of colonies to fixed } \\
\text { volume of broth }\end{array}$} & $\begin{array}{r}298 \\
17 \\
50\end{array}$ & $\begin{array}{r}13215 \\
614 \\
2062\end{array}$ & $\begin{array}{r}780 \\
23 \\
127\end{array}$ & $\begin{array}{l}17 \\
27 \\
16\end{array}$ \\
\hline & 26 & 1062 & 52 & 20 \\
\hline
\end{tabular}


Table 6 Distribution of incorrect results according to method of application of inoculum (combined results for all specimens)

\begin{tabular}{lcccc}
\hline Inoculum applied by & $\begin{array}{l}\text { No of } \\
\text { laboratories }\end{array}$ & \begin{tabular}{l} 
No of results \\
\cline { 2 - 5 }
\end{tabular} & $\begin{array}{l}\text { Ratio of } \\
\text { right:wrong }\end{array}$ \\
\hline Loop & 12 & 575 & 47 & 12 \\
Swab & 262 & 11275 & 682 & 17 \\
Loop followed by swab & 75 & 3403 & 159 & 21 \\
Flooding & 27 & 1000 & 58 & 17 \\
\hline
\end{tabular}

\section{USE OF CONTROLS}

As in the previous trial the 388 laboratories using strains of known sensitivity to control their tests made fewer errors (941 incorrect, 16931 correct results) than the 20 laboratories not using controls (88 incorrect, 755 correct results) $\left(\chi^{2} 41 \cdot 47, p<\right.$ $0.001)$. When controls were used on different plates from the test strains fewer errors $\left(\chi^{2} 9 \cdot 10, p<0 \cdot 01\right)$ were made by the 79 laboratories using daily controls (160 incorrect, 3445 correct results) than by the 89 laboratories using controls either two to three times a week, weekly, or occasionally (222 incorrect, 3471 correct results).

Owing to the additional information provided by the questionnaire used in this trial it was possible to identify three main methods of testing antibiotics. These were: (a) Stokes's and similar methods, in which controls are incubated on the same plate as the test (149 users, 355 incorrect results, 7228 correct); (b) Kirby-Bauer and similar methods, in which sensitivity is defined by strict cut off points (22 users, 38 incorrect results, 713 correct); (c) comparative methods, in which controls are incubated on separate plates ( 53 users, 118 incorrect results, 2657 correct). The error rates associated with the use of these three main methods did not differ from each other significantly.

\section{DISCS}

In the previous trial the results showed an association between error rates and the amount of antibiotic in discs containing ampicillin, erythromycin, or carbenicillin. Results were similar in the present trial, but only with carbenicillin were differences associated with disc content significant (Table 7), although with the other antibiotics differences were nearly significant. There were no signficant differences among the number of errors made by the 176 laboratories using single discs (427 incorrect, 7344 correct results), the 130 laboratories using multiple discs (346 incorrect, 5623 correct results), and the 100 laboratories using a mixture of the two (246 incorrect, 4615 correct results).

\section{MEASUREMENT OF ZONE SIZES}

Laboratories in which zone size was never measured made more errors than those that always did so $\left(\chi^{2}\right.$ $8.08, p<0.01)$ and those that did so only if the zone of the test strain appeared smaller than that of the control $\left(\chi^{2} 7 \cdot 28, p<0 \cdot 01\right)$. There was no difference in error rates between those laboratories always measuring and those measuring only if the test zone was smaller than the control zone (Table 8).

\section{IDENTIFICATION OF POOR PERFORMERS}

Identification of poor performers took place in two stages: demonstration of differences in performance between laboratories followed by identification of laboratories whose performance was significantly below average. Differences in performance among laboratories was tested for by Cochran's $\chi^{2}$ test. This test does not allow missing data and could be applied only to laboratories examining all combinations of antibiotic and organism. A value for Cochran's $\chi^{2}$ test of 263 was obtained for these 155 laboratories during the first six month period and a

Table 7 Distribution of incorrect results according to disc content (combined results for specimens on which relevant antibiotics were tested)

\begin{tabular}{|c|c|c|c|c|c|c|}
\hline \multirow[t]{2}{*}{ Antibiotic } & \multirow{2}{*}{$\begin{array}{l}\text { Disc content } \\
(\mu g)\end{array}$} & \multirow{2}{*}{$\begin{array}{l}\text { No of } \\
\text { laboratories }\end{array}$} & \multicolumn{2}{|c|}{ No of results } & \multirow{2}{*}{$\begin{array}{l}\text { Ratio of } \\
\text { right:wrong }\end{array}$} & \multirow[t]{2}{*}{$x^{2}$} \\
\hline & & & Right & Wrong & & \\
\hline $\begin{array}{l}\text { Ampicillin } \\
\text { Carbenicillin } \\
\text { Erythromycin }\end{array}$ & $\begin{array}{l}10 \mu \mathrm{g} \\
25 / 30 \mu \mathrm{g}^{*} \\
10 / 25 \mu \mathrm{g} \\
100 \mu \mathrm{g}^{*} \\
2 / 2 \cdot 5 / 5 \mu \mathrm{g}^{*} \\
10 / 15 \mu \mathrm{g}\end{array}$ & $\begin{array}{r}40 \\
332 \\
28 \\
274 \\
214 \\
158\end{array}$ & $\begin{array}{r}211 \\
1991 \\
46 \\
655 \\
364 \\
263\end{array}$ & $\begin{array}{r}9 \\
42 \\
21 \\
58 \\
11 \\
16\end{array}$ & $\begin{array}{r}23 \\
47 \\
2 \\
11 \\
33 \\
16\end{array}$ & $\begin{array}{l}3 \cdot 68 \\
\text { NS } \\
36 \cdot 2 \\
p<0.001 \\
3 \cdot 17 \\
\text { NS }\end{array}$ \\
\hline
\end{tabular}

${ }^{*}$ Recommended content. 
Table 8 Distribution of incorrect results according to measurement of zone sizes (combined results for all specimens)

\begin{tabular}{|c|c|c|c|c|}
\hline \multirow{2}{*}{$\begin{array}{l}\text { Measurement of } \\
\text { zone sizes }\end{array}$} & \multirow{2}{*}{$\begin{array}{l}\text { No of } \\
\text { laboratories }\end{array}$} & \multicolumn{2}{|c|}{ No of results } & \multirow{2}{*}{$\begin{array}{l}\text { Ratio of } \\
\text { right:wrong }\end{array}$} \\
\hline & & Right & Wrong & \\
\hline \multirow{2}{*}{$\begin{array}{l}\text { Zone never measured } \\
\text { Zone always measured } \\
\text { Zone measured only if } \\
\text { smaller than control }\end{array}$} & $\begin{array}{r}141 \\
56\end{array}$ & $\begin{array}{l}6289 \\
2115\end{array}$ & $\begin{array}{r}404 \\
98\end{array}$ & $\begin{array}{l}16 \\
22\end{array}$ \\
\hline & 157 & 6815 & 358 & 19 \\
\hline
\end{tabular}

value of 368 for these 164 laboratories in the second six month period, thus showing significant differences in performance among laboratories $(p<$ $0.001)$.

Having established differences in performance between laboratories we analysed the data further to identify laboratories whose performance was significantly below average. The method of analysis used $^{3}$ does not require that all laboratories examine all combinations of antibiotic and organism and could therefore be applied to results from all laboratories. Of the $412 \mathrm{UK}$ and Eire laboratories receiving antibiotic specimens the cumulative scores of 30 laboratories were more than 1.96 standard errors below the mean score in one or both of the two six month periods of the trial and were designated as possible "poor performers." Three of these laboratories were possible "poor performers" in both six month periods. Of the 27 laboratories showing possible "poor performance" in only one six month period 21 had scores below average in the other six month period. The range of the percentage of correct results for these 30 laboratories was 53$82 \%$.

The 30 poorly performing laboratories were compared with other laboratories with respect to their use of methods which in this and the previous trial were associated with correct or incorrect results. The methods considered were: use and frequency of use of controls; disc contents for ampicillin, carbenicillin, and erythromycin; standardisation of inoculum; methods of preparation and application of inoculum; measurement of zone sizes; use of $\mathrm{NaCl}$ or incubation at $30^{\circ} \mathrm{C}$ or both for methicillin testing; and use of lysed blood with DST. A greater proportion of bad methods-that is, those associated with high error rates - were used by the poor performers ( 92 bad methods, 162 good methods) than by other laboratories ( 1121 bad methods, 2711 good methods) $\left(\chi^{2} 5 \cdot 54, \mathrm{p}<0 \cdot 05\right)$.

\section{Discussion}

Most of the findings relating to methods confirm those of the earlier trial and have been discussed in detail previously.' In considering these results we cannot exclude the possibility that results obtained with a method used by a limited number of laboratories may be due to factors other than the method being considered. For this reason firm conclusions on the efficiency of particular methods and practices can be drawn only where corroborative evidence is available from inđependent studies. Thus the effect of such factors as inoculum size, use of lysed blood in testing sulphonamides, incubation at $30^{\circ} \mathrm{C}$ or addition of $\mathrm{NaCl}$ to the medium for methicillin testing, and the use of controls should by now be universally recognised. Strong recommendations have been made for them and should now be effected. But some other findings, such as the differences in error rates apparently associated with the use of various commercially produced culture media, lack such corroborative support and further scientific evidence is needed to test their importance.

The error rates found will have been influenced by the small number of strains used, which were mostly unequivocal in their susceptibility or resistance to the chosen antibiotics. This, together with the fact that quality assessment samples tend to measure the best that laboratories can do rather than the average, indicates a need for caution in relating these results to the error rates likely in routine practice.

There was no evidence of improved performance in the second survey as measured by the results on strains included in both trials. This, as well as the fact that so few laboratories thought it necessary to implement the recommendations made as a result of the first trial, is disappointing. The use of a scoring scheme based on a comparison of each laboratory's results with that of the average result was useful in assessing results from bacteriology specimens for isolation and identification. ${ }^{23}$ The method seems equally applicable to the results of susceptibility testing and, as four to six antibiotics are tested for each strain, the issue of one specimen a month provides sufficient data for assessment of performance at six monthly intervals, as with isolation and identification specimens.

The results of susceptibility testing directly influence patient care. In view of this importance we intend to introduce this scoring scheme for assess- 
ment of antibiotic susceptibility testing as part of the UK external quality assessment scheme. Participants will thus be able to compare their results monthly with those of their peers and, we hope, correct deficiencies as they are revealed. Laboratories with poor performance as indicated by the scoring system over a six month period will be offered help and advice in anonymity and in confidence by the Advisory Panel for Microbiology. ${ }^{2}$

The following recommendations on methods and practices are made on the basis of these two trials ${ }^{1}$ and on supporting evidence which has been publicised over the years. ${ }^{45}$ The apparent association between the use of unsatisfactory methods and poor performance should provide further impetus for change. All microbiologists performing antibiotic susceptibility tests are urged to reconsider their methods in the light of these recommendations.

1 Control organisms should be used each day.

2 Disc contents appropriate to the method practised should be used. In particular, $25 \mu \mathrm{g}$ ampicillin discs for testing organisms from urine, $100 \mu \mathrm{g}$ carbenicillin discs for testing Ps aeruginosa from sites other than urine, and $5 \mu \mathrm{g}$ erythromycin discs for testing $S$ aureus from sites other than urine gave the most reliable results.

3 The inoculum should be standardised to the density recommended for the method used (for the methods most widely used by participants, dense but not confluent growth is required). Emulsifying growth in fluid or subculture to broth followed by application with a loop and spreading with a swab gave the best results. There was some evidence that standardising the inoculum by using opacity tubes gave more reliable results than standardising "by eye" or by using a measured dilution of broth cultures.

4 Zone sizes should be measured rather than assessed "by eye" (at least when smaller than the control zone size if Stokes's method is used).

5 For methicillin testing incubation at $30^{\circ} \mathrm{C}$ or addition of $5 \% \mathrm{NaCl}$ to the medium or both is recommended.

6 Lysed blood should be added to the medium if DST is used for testing sensitivity to sulphonamides and trimethoprim.

We thank members of the antibiotic sensitivity testing subcommittee of the Steering Committee for Quality Control in Microbiology for advice. Members of the subcommittee are: Dr Joan Stokes (chairperson), Dr PR Mortimer (secretary), Mr DFJ Brown, Dr AC Scott, Dr PS Gardner, and Mr JJS Snell.

\section{References}

' Snell JJS, Brown DFJ, Gardner PS. An antibiotic susceptibility testing trial organised as part of the United Kingdom national external microbiological quality assessment scheme. J Clin Pathol 1982;35:1169-76.

${ }^{2}$ Snell JJS, de Mello JV, Gardner PS. The United Kingdom national microbiological quality assessment scheme. $J$ Clin Pathol 1982;35:82-93.

${ }^{3}$ Tillett HE, Crone PB. Quality control of the isolation rate of pathogens in medical microbiology laboratories.J Hyg (Camb) 1976;77:359-67.

${ }^{4}$ Stokes EJ, Waterworth PM. Antibiotic tests by diffusion methods. ACP Broadsheet 55, 1972.

${ }^{5}$ Brown DFJ, Blowers R. Disc methods of sensitivity testing and other semiquantitative methods. In: Reeves DS, Phillips I, Williams JD, Wise R, eds. Laboratory methods in antimicrobial chemotherapy. Edinburgh: Churchill Livingstone, 1978: 8-30.

Requests for reprints to: Dr PS Gardner, Central Public Health Laboratory, Division of Microbiological Reagents and Quality Control, 175 Colindale Avenue, London NW9 5HT, England. 